\title{
المشكلات اللغوية الكتابية لدى متعلمي اللّفة العربيّة في المعاهد العلميّة في باكنبارو ( دراسة تطبيقية )
}

\author{
إسماعيل أعظم \\ جامعة الإسلامية رياو، اندونيسيا \\ akzamalbakanbaru@gmail.com
}

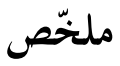

لقد بحث في هذه الدراسة تحليل الأخطاء الكتابية الإملائية التي يقع فيها طلاب المعاهد العلمية المتوسطة

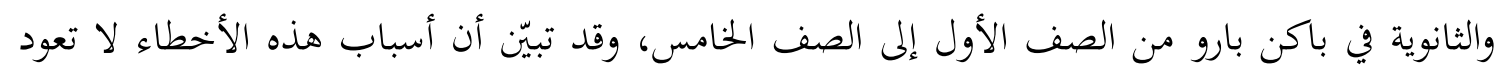

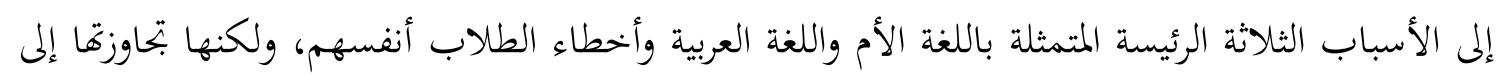

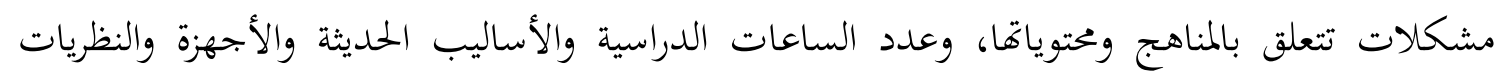

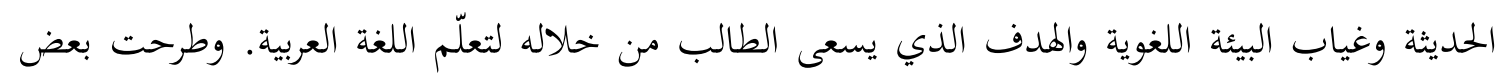

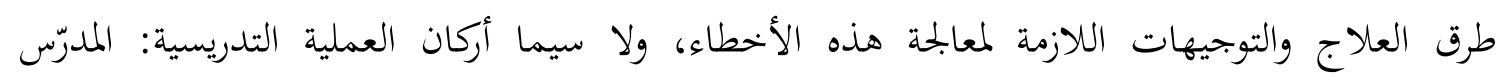

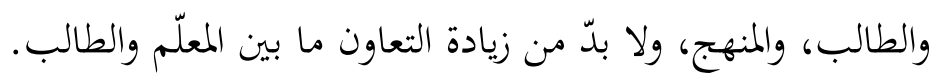

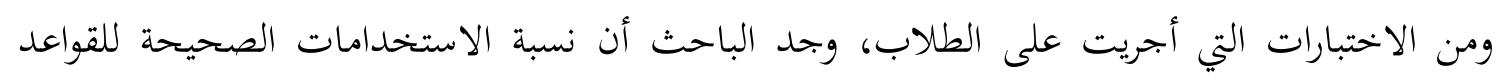

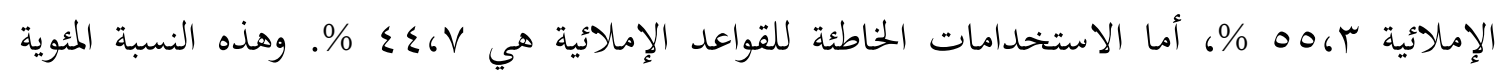

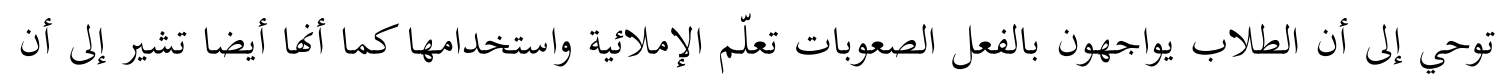

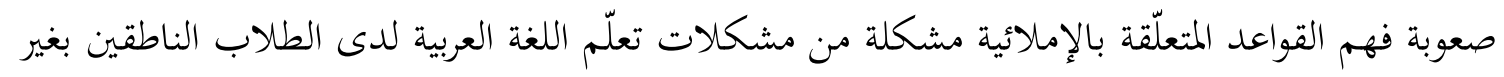

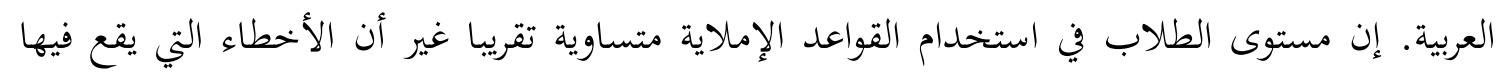

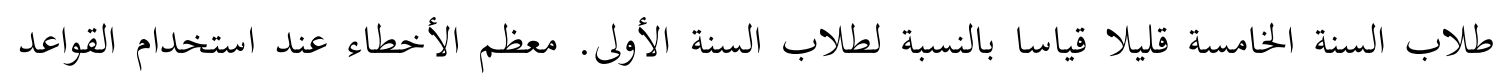

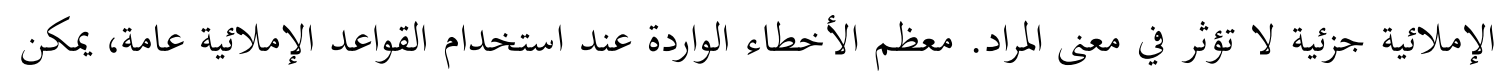

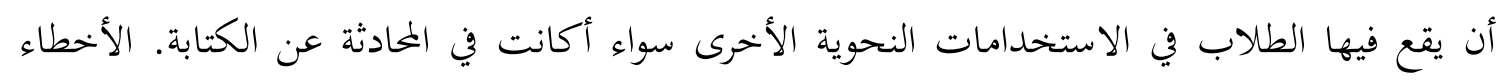

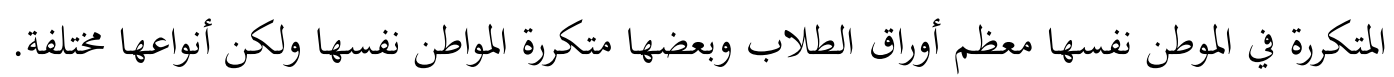




\section{المقدمة}

إنّ عملية تقديم اللغة العربية تعليماً وتعلّماً، في ظلّ الظروف الصعبة التي تواجه الطلبة تستلزم العناية والالتزام تمشياً مع قرار رفع الكفاءات التي غايتها إعلاء كلمة الحق، ونشر الشريعة الإسلامية، ذات الحضارة الفاعلة والمكونات الإيمانية، التي تعلى من قدر وقيمة الإنسان المستخلف لعمارة الكون وفقاً للتصور الإسلامي بغض النظر عن لونه وجنسه. ولذا فإِّ في عملية التعليم والتعلّم مشكلات كثيرة جدا، لا تكمن في المادة التدريسية، ولا في المعلّم، ولا في طريقة التدريس، ولا في المتعلم، ولا في المحيط الاجتماعي الذي تجري فيه العملية التعليمية فحسب، ولكنها نتيجة لوضع تترابط فيه هذه العوامل جميعها.

ومن المعلوم في تعليم وتعلّم اللغات تحقيق الأهداف الأساسية وهي المهارات اللغوية. والمهارات اللغوية هي أربع مهارات (الاستماع - الكاملام - القراءة - الكتابة)، و لما كان لكل علم أهدافه، فإنّ هذه المهارات الأربع في تعليم وتعلم اللغات تمثل الأهداف الأساسية، التي يسعى كل معلم لتحقيقها عند

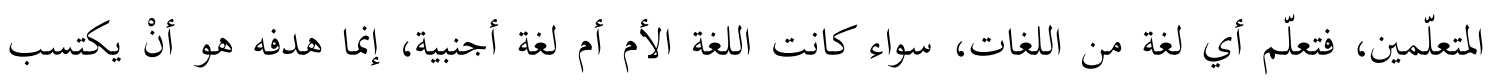

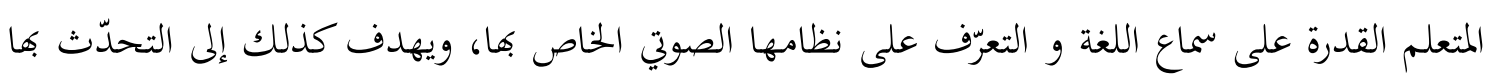
بطريقة سليمة تحقق له القدرة على التعبير عن مقاصده، و التواصل مع الآخرين أبناء تلك اللغة خاصة، و كذلك يسعى إلى أنْ يكون قادرا على قراءها و كتابتها. تأتي مهارة الكتابة متأخرة بحسب ترتيبها بين بقية المهارات، فهي تأتي بعد مهارة القراءة. ونشير هنا إلى أنّ الكتابة عملية ذات شقين، أحدهما آلي، والآخر عقلي. والشق الآلي يحتوي على المهارات الآلية (الحرّكية) الخاصة برسم حروف اللغة العربية، ومعرفة التهجئة، والترقيم في العربية. أما الجانب العقلي، فيتطلب المعرفة الجيدة بالنحو، والمفردات، واستخدام اللغة .يقصد بالمهارات الآلية في الكتابة العربية، النواحي الشكلية الثابتة في لغة الكتابة، مثل علامات الترقيم، ورسم الحروف وأشكالها، والحروف التي يتصل بعضها ببعض، وتلك التي تتصل بحروف سابقة لما، ولا تتصل بحروف لاحقة. ومن الشَّقِّ الآلي أيضاً، رسم الحركات فوق الحرف، أو تحته، أو في فايته، ورسم، أو عدم رسم همزات القطع والوصل. وهذه

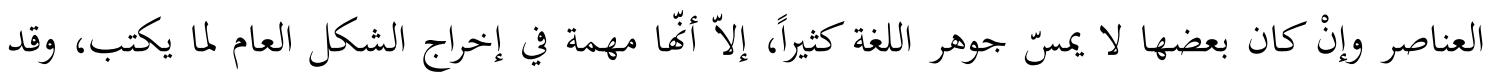
يحدث إسقاطها-أحياناً- لبساً، أو غموضاً في المعنى. عند عرض مهارة الكتابة، ينبغي البدء بالجانب الآلي تدريجياً، ثم التوسع رويداً رويداً، وذلك لمساعدة الطلاب على تعرف الشكل المكتوب للكلمة العربية.

' أحمد مشاري العدواني، اللغات الأجنبية تعليمها وتعلمها، ، (الكويت: البحلس الوطني للثقافة والفنون والآداب، طا، د- ت)، ص : 7.

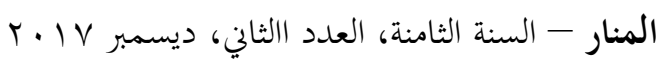


لكل لغة ظواهر تميز كتابتها. ومن أهم ظواهر اللغة العربية، التي يركز عليها المعلم ويوليها أهمية عند تدريبه الطلاب على الجانب الآلي من الكتابة ما يلي: الضبط بالشكل (أي وضع الحركات القصيرة على الحروف) وبتريد الحرف، والمد، والتنوين، والشدة، و(ال) الشمسية، و(ال) القمرية، والتاء المفتوحة والمربوطة، والحروف التي تكتب ولا تنطق، والحروف التي تنطق ولا تكتب، والهمزات.

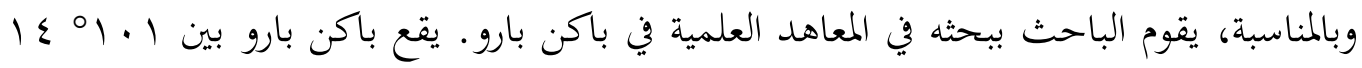

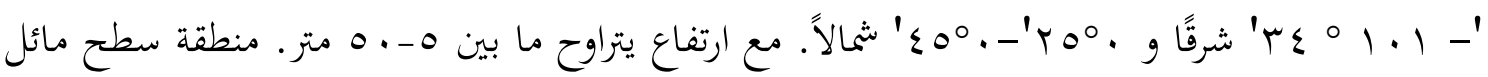
الشمالية ومتموجة على ارتفاع يتراوح بين ه-11 1 مترا. ب باكن بارو هي العاصمة واكبر مدينة في رياو في إندونيسيا. المدينة هي مدينة التجارة والخدمات، هي مدينة فيها معدل النمو والهجرة والتحضر مرتفعة. المركز الثقافي الملايو هو انعكاس للحضارة من أجل القيم الثقافية النبيلة بحتمعات مستقرة مدينة باكن بارو في المحافظة، ويعيش ثقافة الملايو و الممارسة وتطوير ثقافة الملايو. سوف بتعل من مدينة باكن بارو كمركز لثقافة الملايو، من بين أمور أخرى، وستوجه إلى المظهر المادي للهوية المبني الذي يعكس السمات في المنطقة، في محال الهوية الأصلية، وأكثر صلابة تم حفرها في حياة الجمارك الملايوية من القيم النبيلة من عادة الملايو. ْالثقافة الملايوية والثقافات الإسلامية مرادفا، لذلك طلبة المعاهد العلميّة في مدينة باكن بارو لمواصلة دراستهم في الشرق الأوسط، وخاصة في الجامعة الإسلامية في المدينة المنوّرة وجامعة الأزهر الشريف في مصر. ثم أكملت الدراسة أفم يقومون الدعوة الإسلامية ببناء المدارس والمعاهد العلمية التي تستخدم اللغة العربية في جميع الدراسات. تعريف ومنزلة الإملاء وأهميته مفهوم الإملاء: هو ذلك العلم الذي يعنى بالقواعد الاصطلاحية التي بمعفتها يحفظ قلم الكاتب من الزيادة والنقصان، ويهتم بأمور محددة: (منها كيفية كتابة الهمزة في أول الكلمة ووسطها وآخرها)، وكذا الألف اللينة، ويفرق بين (التاء المربوطة والمبسوطة) كما يهتم بالأحرف التي تزاد والتي تحذف من الألفاظ، والتنوين وأنواع اللام إلى غير ذلك من أمور ترقى بمستوى الكاتب إلى الصحة اللغوية المنشودة بحيث تخلو كتابته من الأخطاء الإملائية التي تشيع في كتابات الدارسين والمثقفين. ` إذن، الإملاء هو عملية التدريب

'ُ دليل عمل في إعداد المواد التعليمية لبرامج تعليم اللغة، إعداد جامعة الملك سعود، الرياض، بدون طبعة، بدون سنة، ص: 11 ا. 1. r http://www.pekanbaru.go.id

\section{؛ http://id.wikipedia.org/wiki/Kota_Pekanbaru}

- http://www.pekanbaru.go.id

' تحسين مهارة الإملاء في اللغة العربية للصف الأول الإعدادى، أحمد محمد محمود ندا، مدرسة دمياط الإعدادية للبنين، العام الدراسي

$\cdot r \cdot 1 \cdot-r \cdot \cdot q$ 
على الكتابة الصحيحة لتصبح عادة يعتادها المتعلم، ويتمكن بواسطتها من نقل آرائه ومشاعره وحاجاته وما يُطلب إليه نقله إلى الآخرين بطريقة صحيحة. اسم هذا الفن يسمي هذا الفن : الكتابة، والخط، والهجاء، ورسم الحروف. كما يسمي: الإملاء

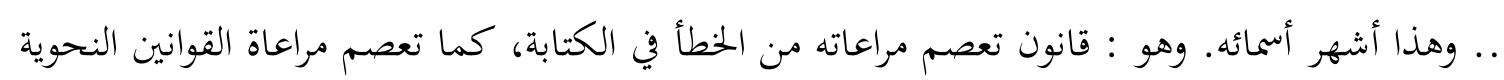

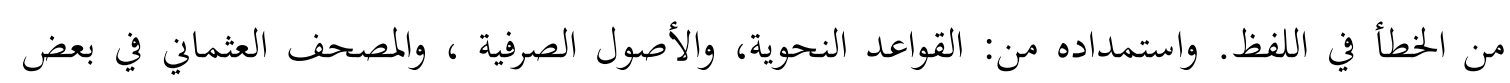
كلماته، ومن اللغة. ` للإملاء منزلة كبيرة بين فروع اللغة، فهو من الأسس المامة للتعبير الكتابي، وإذاكانت القواعد النحوية والصرفية وسيلة لصحة الكتابة من النواحى الإعرابية والاشتقاقية ونحوها، فإن الإملاء وسيلة

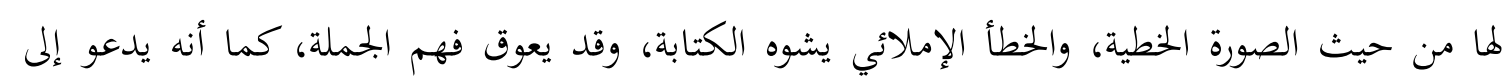
احتقار الكاتب وازدرائه.

والإملاء بالنسبة لصغار التلاميذ مقياس دقيق للمستوى الذي وصلوا إليه في التعلّم، ونستطيع في سهولة - أن نحكم على مستوى الطفل بعد أن ننظر إلى كراسته التي يكتب فيها قطع الإملاء. ^ ومن الواضح أن فن الإملاء قد تدرّج في مدارج شتى، واعتراه إصلاح وتنقيح، حتى انتهى إلى الوضع الأخير الذي يتمثل فيما صار إلينا، وهو وضع حاول بعض الناس وبعض الهيئات أن ينال منه فلم يضره شيئا، وذلك لأنه قد بنى على أسس وثيقة مطردة، ولأن عوامل التنقيح والإصلاح من قبل لم تدع فيه بجالا لما

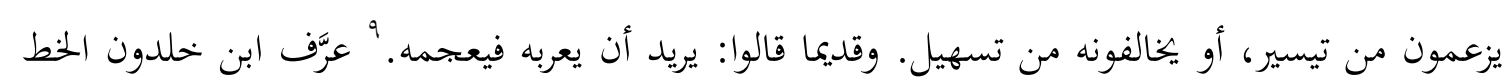

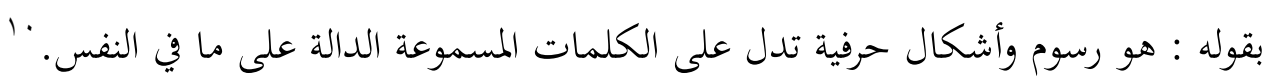
وفي المعنى الآخر، هو نظام لغوي معين- مثله في ذلك مثل النظام النحوي، والنظام الصري،، والنظام الدلالي، والنظام الصوتي- موضوعه الكلمات التي يجب فصلها، وتلك التي يجب وصلها، والحروف التي تزاد والحروف التي تحذف، والهمزة بأنواعها المختلفة، سواء كانت مفردة أو على أحد حروف اللين الثلاثة، والألف اللينة وهاء التأنيث، وتاؤه، وعلامات الترقيم، ومصطلحات المواد الدراسية، والتنوين وأنواعه، والمد بأنواعه، وقلب الحركات الثلاث، وإبدال الحروف، واللام الشمسية والقمرية، ووظيفة الإملاء في أنه يعطي صورا بصرية للكلمات تقوم مقام الصور السمعية عند تعذر الاستماع. أهمية الإملاء:

\footnotetext{
${ }^{v}$ http://www.hadielislam.com/articles/articles.php?mod=subcategory\&c=rr $\mid \wedge$
}

$$
\begin{aligned}
& \text { ^ الموجه الفنى لمدرسى اللغة العربية، عبد العليم إبراهيم، دار المعارف بمصر، الطبعة العاشرة، ص: بو 1، 14 } 9 \text { ام. }
\end{aligned}
$$

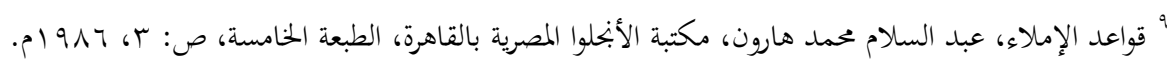

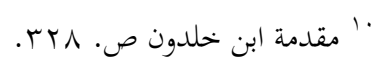


الإملاء جزء مهم من الكتابة العببية، وهو من الأسس المهمة في التعبير الكتابي، وإذا كانت قواعد النحو والصرف وسيلة لصحة الكتابة نويا واشتقاقيا، فالإملاء وسيلة لها من حيث الصنية الصورة الخطية،

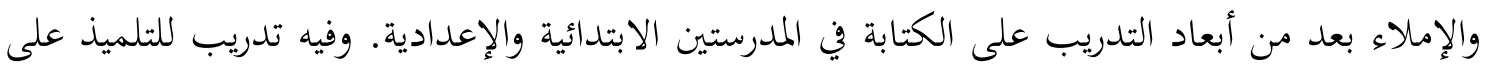

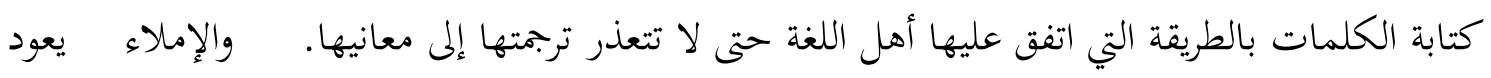

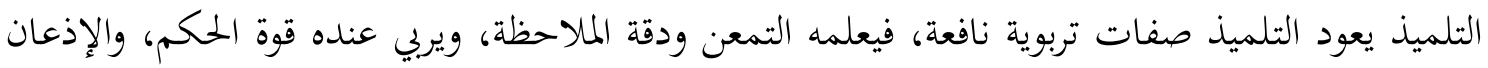

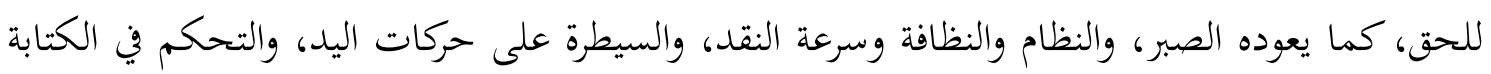

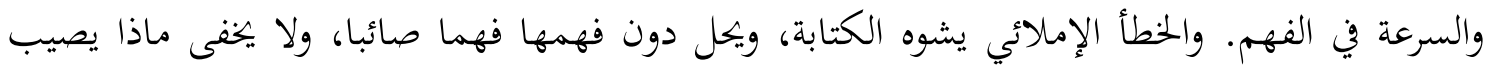

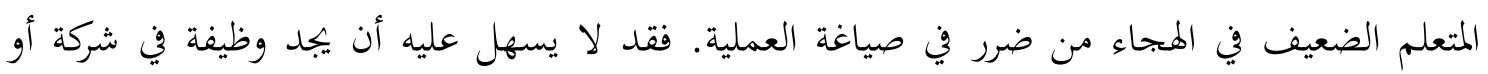

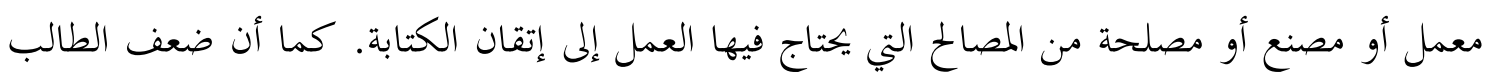

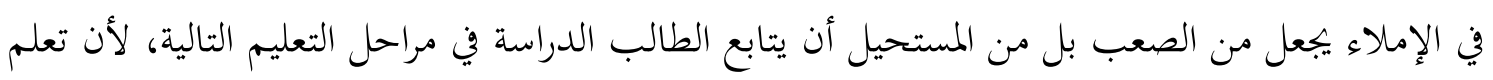

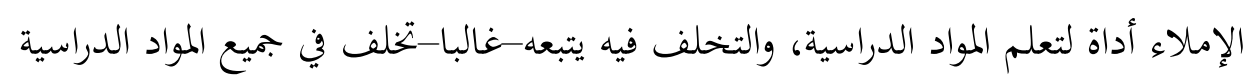

أنواع الإملاء وطريقة تدريسه - الإملاء المنقول الإكاء وطرة

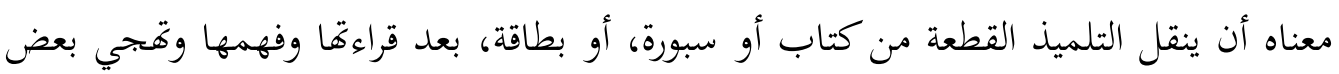

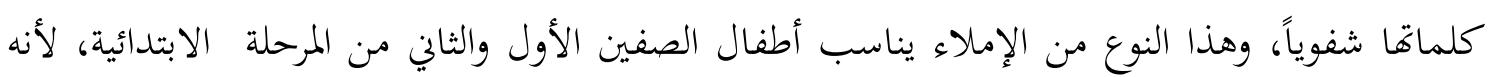

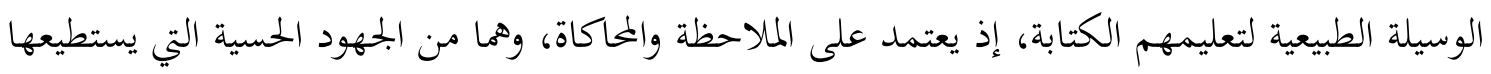

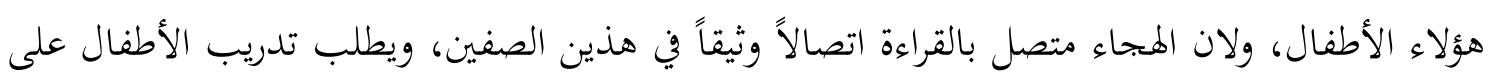
القراءة وعلى كتابة ما يقروون في وقت واحد أو في وقتين متقاربين.

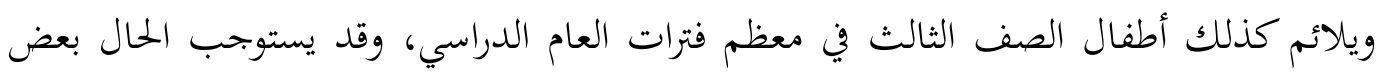
التلاميذ الضعفاء في الصف الرابع، أن يمتد تدريبهم على الإملاء المنقول، في واجبات الصفات منزلية.

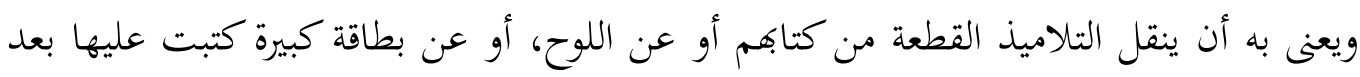

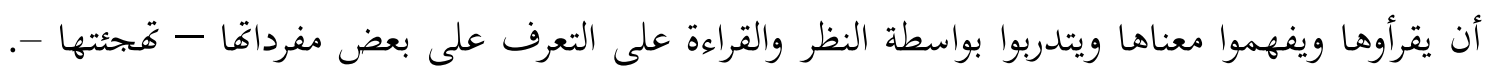

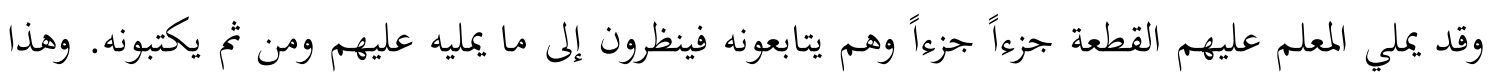

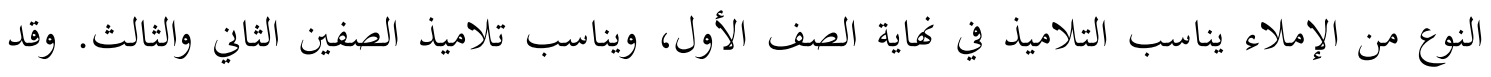
يُلجأ إليه مع بعض الطلبة الضعفاء في صفوف أخرى. طريقة الثدريس يسير المعلم على حسب الخطوات التالية : 
ا- التمهيد لموضوع القطعة، بقراءقا وفهمها قبل الكتابة فإذا كان الموضوع جديداً لم تسبق قراءته (وهذا في الصف الثالث) يستخدم في التمهيد عرض النماذج أو الصور أو الأسئلة الممهدة لفهم الموضوع. ץ- عرض القطعة في الكتاب، أو البطاقات، أو على السبورة دون ضبط للكلمات، حتى لا ينقل التلاميذ هذا الضبط، ويتورطوا في سلسلة من الأخطاء، وتشق عليهم الملاحظة والمحاكاة من جراء هذه الصعوبات المتراكمة.

ب- قراءة المعلم القطعة قراءة نموذجية. ع- قراءات فردية من التلاميذ، حملاً على مزيد من دقة الملاحظة، ويجب الحرص على عدم مقاطعة القارىء، لإصلاح خطأ في الضبط. ه- أسئلة في معنى القطعة، للتأكد من فهمهم لأفكارها وهذه الخطوة تدرب التلاميذ على التعبير الشفوي الذي يجب أن يكون له نصيب في كل درس. 1- هجي الكلمات الصعبة التي في القطعة، وكلمات أخرى مشابهه ويحسن تمييز هذه الكلمات إما بوضع خط تحتها، وإما كتابتها بلون مخالف أو وضعها بين قوسين وطريقة هذا التهجي أن يشير المعلم إلى الكلمة، ويطلب من كل تلميذ قراءةا، وقهي حروفها، ثم ينتقل إلى كلمة أخرى.

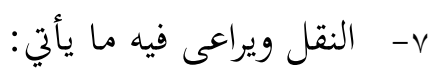

$$
\text { (أ) إخراج الكراسات وأدوات الكتابة وكتابة العنوان والتاريخين نقلاً عن السبورة }
$$

(ب) أن يملي المعلم على التلاميذ القطعة كلمة كلمة، مشيراً في الوقت نفسه إلى هذه الكلمات على

$$
\text { السبورة الإضافية. }
$$

(ج) أن يسير جميع الطلاب معاً في الكتابة، وأن يقطع المعلم السبيل على التلاميذ الذين يميلون إلى إلى

$$
\text { التباهي بالانتهاء من الكتابة قبل غيرهم. }
$$

1- قراءة المعلم القطعة مرة أخرى، ليصلح التلاميذ ما وقعوا فيه من أخطاء ليتداركوا ما فاهم من نقص. 9- جمع الكراسات بطريقة منظمة وهادئة. • ا- إذا بقى من الحصة شيء من الوقت، يمكن شغل التلاميذ بعمل آخر مفيد مثل تحسين الخط أو مناقشة معنى القطعة. تقويم (تصحيح) الإملاء توجد عدة طرائق لتقويم هجاء الطلاب، وهي:

تقويم المعلم المباشر لكتابات الطلاب داخل الفصل: ويتمثل ذلك بتقويم المعلم لكتابات الطلاب أمامهم داخل الفصل وأن يقوم بتحديد أخطاء الطلاب وكتابة صواب كل خطأ، ولا شك أن هذه الطريقة تؤدي إلى إرشاد كل طالب إلى الصواب، 
ومعرفة خطئه، كما تتميز بنوع من الاتصال والتفاعل بين المعلم وطلابه، ويتمشى هذا مع القاعدة التربوية

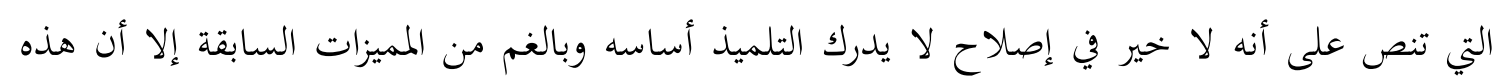

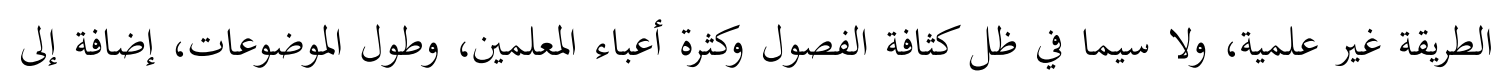

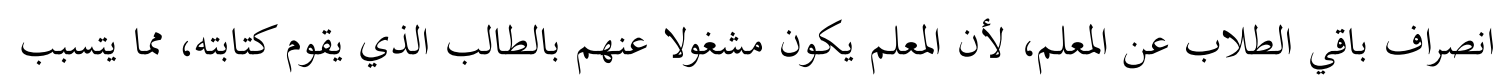
في مشكلات في إدارة الفصل. ونتيجة للعيوب السابقة انصرف المدرسون عن تقويم كل أعمال الطلاب، واكتفوا فقط بتقويم

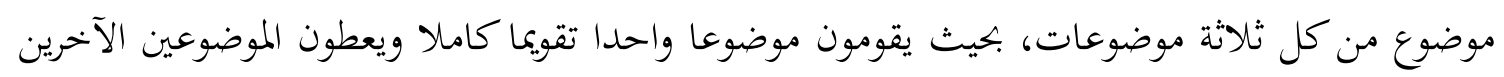

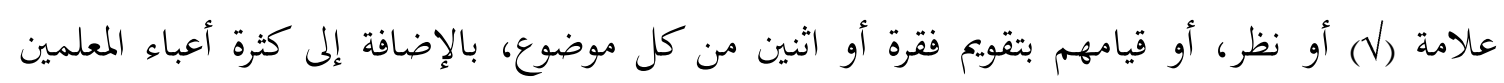

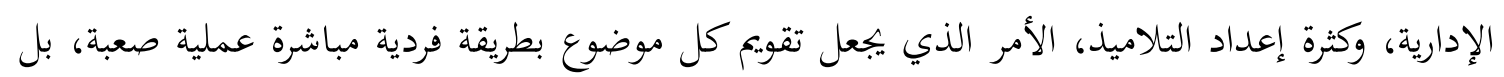

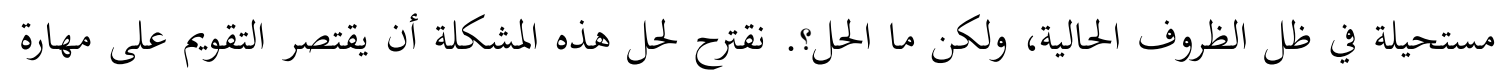

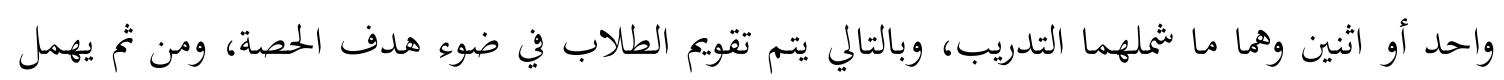

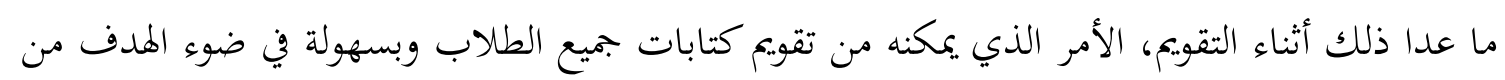

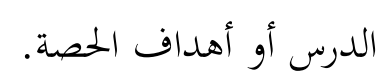

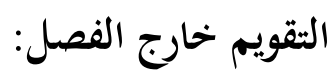

حيث يجمع المعلم الكراسات ويقومها خارج الفصل، على يكتب صواب الكلمة الخطأ فوقها.

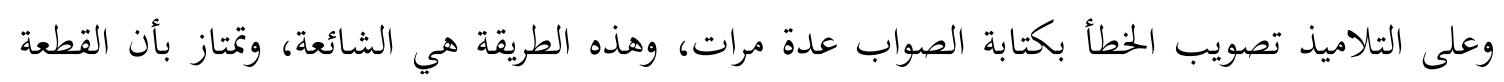

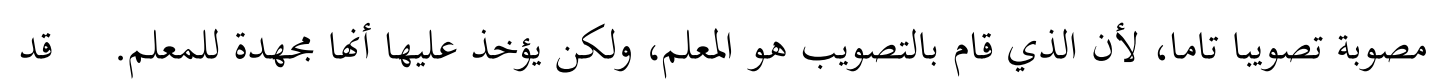

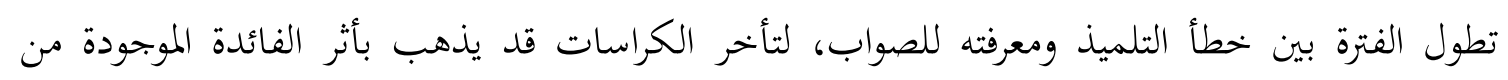
التقويم.

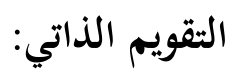
وتتمثل في قيام الطالب بتقويم كتابته بنفسه دون الرجوع إلى معلمه أو زملائه ويستند في تقويمه

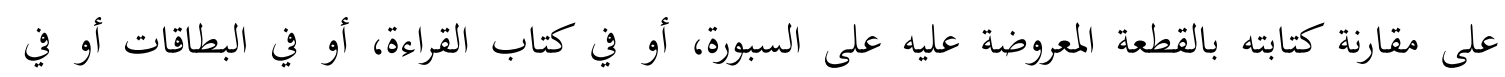

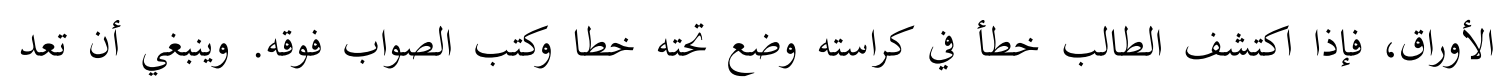

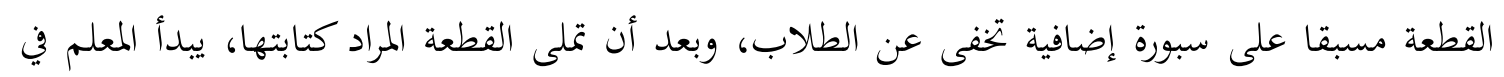

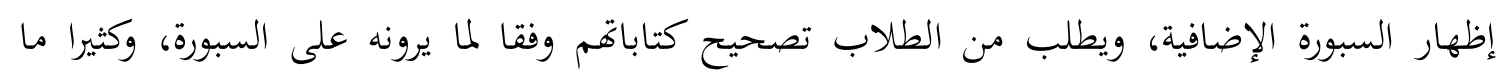

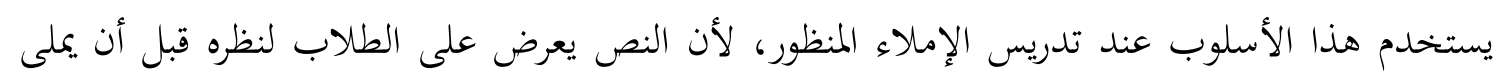
عليهم 
ومن نميزات هذه الطريقة أها تساعد التلاميذ على دقة الملاحظة وتعودهم الثقة بأنفسهم والاعتماد عليها، كما تعودهم الصدق والأمانة، وتقدير المسئولية والشجاعة في الاعتراف بالخطأ، وتحري الأخطاء التي وقعوا فيها وإصلاحها من تلقاء أنفسهم، ولا شك أن في هذه الطريق - لو نفذت بطريقة صحيحة - تنمية للجوانب الأخلاقية لدى الطلاب. وينبغي الحذر عند استخدام هذه الطريقة، لأن بعض الطلاب قد لا يدرك سبب الخطأ، كما أن بعض الطلاب قد يتحرج من إظهار أخطائه فيترك بعض الكلمات دون تصويب، ولتلافي هذه الأخطاء يأحذ المعلم بعض الكراسات العشوائية ويقومها مرة ثانية. تقويم الأقران: وتتمثل في قيام الطلاب بتقويم كتابات زملائهم، تحت توجيه المعلم، وبهذا يتحرر المعلم من تقويم كتابة كل طالب، ويتفرغ لإعطائهم أنشطة مكثفة. حيث يتبادل الطلاب كراسات الإملاء فيما بينهم ليراجع كل مهم كراسة زميله، وذلك أما بمقارنتها بالقطعة المدونة على السبورة الإضافية، وأما بمقابلتها بالكتاب الذي أمليت منه، وبعد التقويم ترد الكراسات إلى أصحابها، ليعرف كل تلميذ خطأه ويعمل على

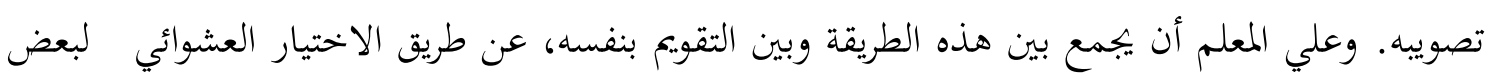
الكتابات المقومة، ويقومها مرة أخرى حتى يتجنب المثالب التي يمكن أن تتصف بهـ هذا هذه الطريقة. يوجد ابتحاهان في تقدير درجات الطلاب في الإملاء:

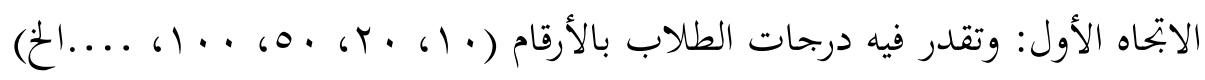
الاتحاه الثاني: ويتم فيه تقدير درجات الطلاب بالأوصاف (حسن، جيد، مقبول، ممتاز، ... الخام)

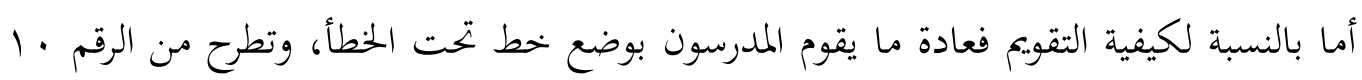
لتكون بسط الكسر، ورقم · 1 هو مقام هذا الكسر، فلو فرضنا أن تلميذ اخطأ في و كلمات، تكون درجته • 1/1، أي درجة واحدة. ولكن هذا الإجراء ليس له أساس علمي، ولذا يلجأ المتخصصون إلى أحد الأسلوبين الآتيين في التقويم: 1- أن يطرح الخطأ من عدد الكلمات الإملائي، فإذا كان عدد الكلمات مثلا عشر كلمات وأخطأ الطالب في كلمة واحدة، يطرح هذا الخطأ من عدد الكلمات الإجمالي. ז- يحسب عدد كلمات القطعة، وليكن . . . كلمة، فإذا أخطأ التلميذ في كلمة تخصم من المائة، وتعتبر المائة هي مقام الكسر، والبسط عدد الكلمات التي لم يخطئ فيها التلميذ، فإذا أخطأ التلميذ مثلا في خمس كلمات فتكون درجته هكذا و9 190 . . 1.

طلاب المعاهد العلمية باكنبارو قد اختار الباحث طلاب المعاهد العلمية الذين يدرسون في المستوى الثانوي العالي، وهم طلاب المعاهد السنة الرابعة والسنة الخامسة بالمعاهد الآتية: معهد عمر بن الخطاب، ومعهد الفرقان، وطلاب 
السنة الأولى والثانية من المستوى المتوسطة بمعهد الأسوة. وعددهم جميعا V• ا طالبا تعرض في الجدول الآتي على شكل إحصائيات إبمالية:

جدول (1)

\begin{tabular}{|c|c|c|c|c|}
\hline \multicolumn{5}{|c|}{ إحصائيات إجمالية } \\
\hline & & الصف الدراسي & الفصل & اسم المدرسة \\
\hline \multirow[t]{2}{*}{ حדה } & مضبوط & $1 . v$ & $1 . v$ & $1 . v$ \\
\hline & مفقود & . & . & . \\
\hline وسط & & $r, r Y Y \mid \cdot r \lambda \cdot \varepsilon$ & r & \\
\hline \multicolumn{2}{|c|}{ الانخراف المعياري } & $1,001 \mathrm{~V} 0911 \mathrm{~N}$ & . & \\
\hline
\end{tabular}

الأسباب المؤدّية إلى اختيار هؤلاء الطلاب:

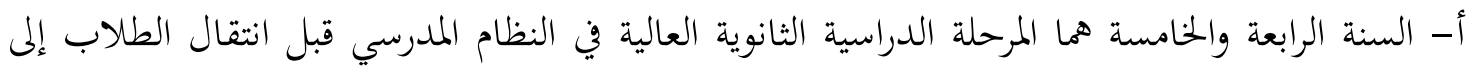
المرحلة الجامعية.

ب- كلّ الطلاب يتكلمّون لغة واحدة وهي اللغة الإندونيسية اللغة الأم.

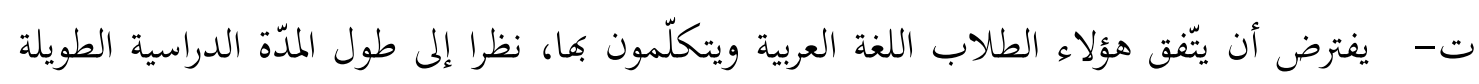

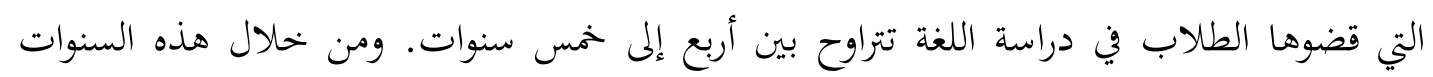

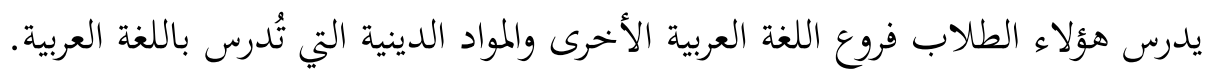
ث- واختار الباحث طلاب في المستوى الأوّل وهم من الطلاب المتوسطة أكاديميا.

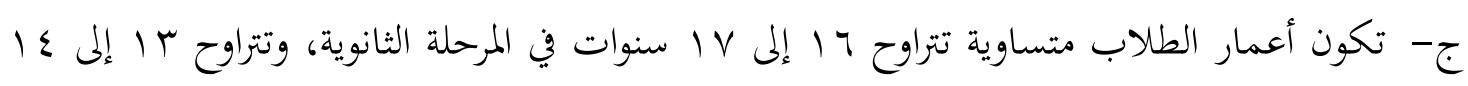
سنوات.

\section{عرض وتحليل الاستبيانات ونتائجها}

يهتمّ هذا الفصل بالدراسة التطبيقية لظواهر الأخطاء الواقعة لدى طلاب المعاهد العلمية في باكن

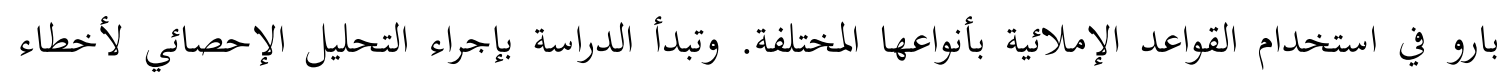

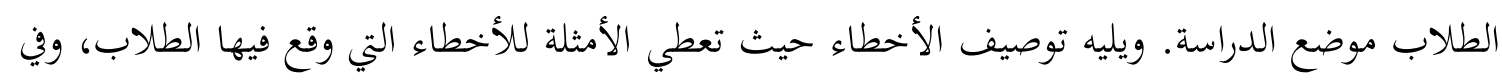

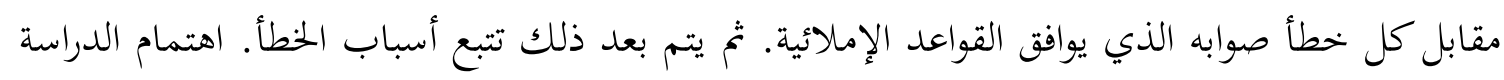

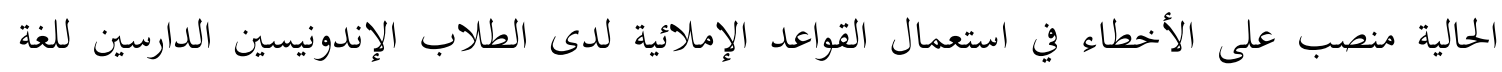

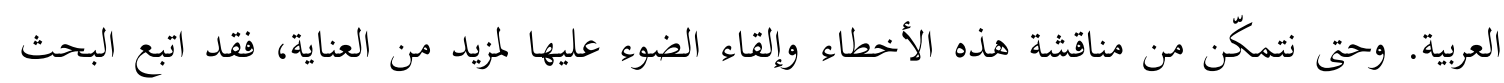
الحالي عدة خطوات لتمكّن من حصر هذه الأخطاء، وهذا باتباع الخطوات التالية: 
() يؤخذ بالخطأ لمرّة واحدة فقط لدى الطلاب، حتى وإن جاء هذا الخطأ أكثر من مرة.

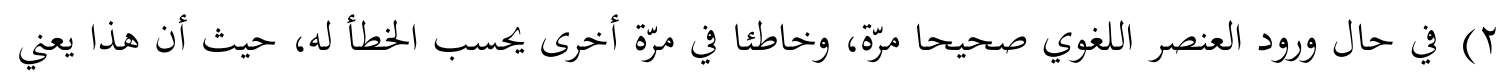
عدم تمكّن الطالب من القاعدة الإملائية الصحيحة الخاصة بنقطة البحث والإحصاء. والدراسة الحالية لا تمدف إلى حصر أخطاء الأفراد بذاتم بمعنى مدى تكرار الخطأ لدى الفرد

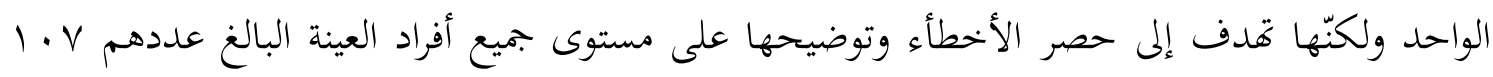
طالب في المستوى المتقدم من دراسة اللغة العربية. ومن ثمّ بيان الأخطأ المتكرّرة في جميع العمليات اللغوية والتي تمثل صعوبة لغوية لدى هؤلاء الطلاب. ويدلّ التحليل الإحصائي على أن عدد الأخطاء في هذه الدراسة بلغ ع وب خطأ، وتوزّعت الأخطاء إلى اثنين عشر قسما رئيسة، وهي: الهمزة في أول الكلمة، بدل النقطة حرفا واحدا من هذه الحروف الخمسة، همزة القطع، همة الوصل، ألفا لينة، تاء مفتوحة أو تاء

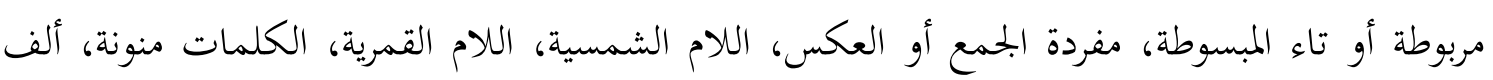
مقصورة، وألف ممدودة. وبحدر الإشارة هنا على الجحدول الآتي يوضح عدد الأخطاء في كل قسم. ويعرض هذا الفصل الدراسة التطبيقيّة الميدانيّة التي تناول فيها الباحث تحليل نتائجها وتفسيرها.

\section{خاتمة ومقترحات}

يرتكب الطلاب الأخطاء لأسباب عديدة. فمن الأسباب التي تؤدي إلى الأخطاء في استخدام

$$
\text { القواعد الإملائية هي: }
$$

$$
\begin{aligned}
& 1 \text { - ضعف مقدرة الطلاب على التعبير السليم عن المعنى المراد، ويشمل: } \\
& \text { - - عدم تركيز الطلاب عند التعلّم كيفية كتابة الإملائية. } \\
& \text { - التردّد في استرجاع المعاني الدلالية وإعطائها. }
\end{aligned}
$$

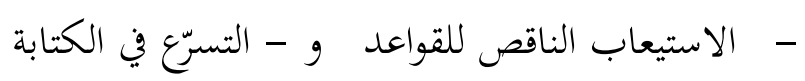

$$
\begin{aligned}
& \text { r - ضعف مقدرة المعلّمين في تعليم اللغة العربية الذي يشمل: } \\
& \text { - - أن عدد المعلّمين الذين يدرّسون مادة اللغة العربية والنحوية قليل. }
\end{aligned}
$$

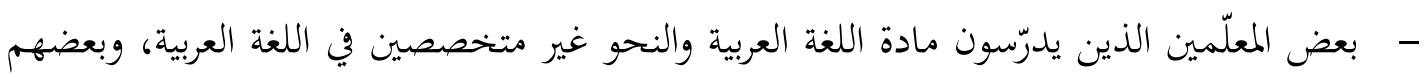

$$
\text { ب- عدميّدون بتعليم المواد الأكاديمية الأخرى. }
$$

- لقد استورد مقرر المواد العربية والكتب الدراسية في المعاهد العلمية المتوسطة والثناوية بإندونيسيا. ولا شكّ أن هذا المقرّر وهذه الكتب لا تتناسب مع مستوى الطلاب الإندونيسين وبيئتهم. 
- - إن اللغة المستخدمة في الكتاب عالية لا تناسب المستوى اللغوي عند الطلاب الإندونيسين، كما أن الأمثلة التوضيحية غير ملائمة للمواقف الاجتماعية لدى الطلاب إذ يؤدي ذلك إلى حفظ

$$
\begin{aligned}
& \text { القواعد النحوية والإملائية والأمثلة كما هي بدون فهمها الصحيح. } \\
& \text { ع - الفهم الناقص بالقواعد الإملاية لدى المعلّمين والطلاب وهو يشمل: } \\
& \text { - - الفهم الناقص بالغرض من استخدام الإملائية. } \\
& \text { - الفهم الناقص بمعاني الإملائية و - الفهم الناقص بقواعدها } \\
& \text { هـ - التأثر باللغة الأم لدى المعلّمين والطلاب. وهو يشمل: } \\
& \text { - - عدم انتباه إلى الاختلافات ما بين اللغتين الإندونيسية والعربية } \\
& \text { - - النقل السلبي لنظام الإماء من اللغة الإندونيسية إلى اللغة العربية } \\
& \text { - - تأثير الترجمة الحرفية من اللغة الإندونيسية إلى اللغة العربية. }
\end{aligned}
$$$$
\text { المراجع والمصادر }
$$

العدواني، أحمد مشاري، اللغات الأجنبية تعليمها وتعلمها، (الكويت: المحلس الوطني للثقافة والفنون

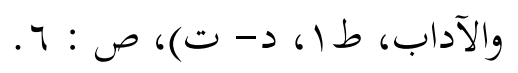

دليل عمل في إعداد المواد الثعليمية لبرامج تعليم اللغة، إعداد جامعة الملك سعود، الرياض، بدون

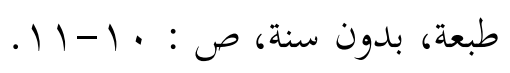

ندا، أحمد محمد محمود، تحسين مهارة الإملاء في اللغة العربية للصف الأول الإعدادي، مدرسة

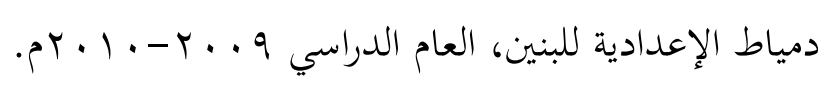

إبراهيم، عبد العليم، الموجه الفنى لمدرلسى اللغة العربية، دار المعارف بمصر، الطبعة العاشرة، ص:

.019716194

هارون، عبد السلام محمد، قواعد الإملاء، مكتبة الأبحلوا المصرية بالقاهرة، الطبعة الخامسة، ص: ؟ا،

. 1917

هيريمبوى، راشد عبد الحميد، تلدريس مهارة الكتابة العربية للراشلدين غير الناطقين بالعبية (نماذج باستخدام الوسائل البصرية للمستوى المبتدى)، بحث تكميلي لنيل درجة الماجستير في اللغة العربية بوصفها لغة ثانية، (كوالا لمبور: الجحامعة الإسلامية العالمية، لو9 19 م). غزالي، حانيزم محمد، الأخطاء اللغوية الكتابية لدى الطلاب الملايويين في التخحدام المصلدر، بحث تكميلي لنيل درجة الماجستير في اللغة العربية بوصفها لغة ثانية، (كوالا لمبور: الجامعة الإسلامية

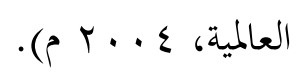


- Abdalla, Adil El-Sheikh,. An error analysis of the written Arabic of Malay students, ( A Thesis Submitted to the Faculty of Language and Linguistic University of Malaya in Fulfillment of the Requirements for the Degree of Doctorate in Philosophy), University of Malaya, Kuala Lumpur, 1997.

- Krijcie, R.V., and Morgan, D.W. Determining sample size for research activities. Educational and Psychological Measurement, published by the research division of the National Education Association, p. $r \cdot, 7 \cdot V_{-} 71 \cdot, 19 \vee \cdot$.

- http://www.pekanbaru.go.id

- http://id.wikipedia.org/wiki/Kota_Pekanbaru

- http://www.hadielislam.com/articles/articles.php?mod=subcategory\&c=rr $/ \wedge$ 